\title{
Features of the State Anti-Doping Policy of the Republic of Tatarstan in the World Sports Trends' Context
}

\author{
Fedorova O.V. \\ Kazan University of Management "TISBI" \\ Kazan, Russia \\ fedorovfamily@mail.ru
}

\author{
Mylnikov M.M. \\ Kazan University of Management "TISBI" \\ Kazan, Russia \\ mylnikov_maxim@mail.ru
}

\author{
Nabieva K.I. \\ Kazan University of Management "TISBI" \\ Kazan, Russia \\ karfagen2004@mail.ru
}

\begin{abstract}
The article deals with the issues of sports achievements and failures as factors of national image construction, the use of sport as a resource of political influence on society, the use of anti-doping programs in public policy at different levels as a mean of opposing to negative facility effects. The article presents the results of international law rules, protocols and sectoral programs analysis. The results of academic discussions on sports public influence and a problem of doping use. Information sources analysis and summarizing, casestudy and comparative methods, methods of analysis and synthesis. We considered and analyzed the issue of regional sports infrastructure modernization in a necessity of tough anti-doping control and improved transparency. Implementation of anti-doping control and education programs, including development of federal subjects' sports infrastructure may provide opportunities for further success of Russian athletes in international competitions.
\end{abstract}

Keywords-sport; doping; anti-doping policy; antidoping education; Republic of Tatarstan; RUSADA.

\section{INTORDUCTION}

Modern professional sport is undoubtedly a large-scale industry that combines commercial activity and business organization, markets of sports goods and services, media products and technological scientific research [2]. Besides, professional sport appears to be one of the most influential resources of politics. Staging sports mega-events potentially provides emerging powers with opportunities to generate attraction even where they possess unattractive domestic political characteristics, and we suggest that there is growing evidence to suggest that the international dimension of sporting success - be it national teams and national representatives abroad or staging a sports megaevent - is one arena in which the politics of attraction is played out through soft power [3,4]. Accordingly, sport today is both a cultural heritage and a subject of national pride, a strong political capital and an effective instrument of political life.

Currently, it is necessary to recognize the organized purposeful attempts aimed at damage of image some nation states initiated by powerful actors with high international authority. Such attempts are carried out also through reduction of sports achievements' importance or even complete sports competitions results` cancellation, based on suspicion of doping use by athletes. In the period from 2014 to 2019, the sports federations of Russia and the Russian anti-doping agency "RUSADA" became the main target of such information attacks.

Among the most notable events that made the social and political image of Russia worse through sports - the fact of emigration and subsequent controversial statements of the Moscow anti-doping laboratory`s former chief Gregory Rodchenkov, urgent reports of the Richard McLaren's Commission, deprivation of Olympic Games-2014 awards, isolating the Russian para-Olympic national team from the 2018 Winter Olympics in Pyongyang, prohibition of the Olympic national team of Russia to act under the banner of the state. Also under threat of postponement was the FIFA World Cup, which was held by Russia in the summer of 2018 [5].

The doping scandal in the Russian professional sports broke out in 2015-2016. Warring statements of Western mass media, politicians and sports officials were aimed at accusing the Russian Federation of implementing a largescale state program aimed at systematic adoption of performance enhancement drugs by Russian athletes. The reason for the scandal was the documentary film of German journalist Hayo Zeppelt "Secrets about doping: How Russia makes its winners", presented in December 2014 on the German TV channel ARD. 
In parallel, a "meldonium scandal" was projected and implemented, while the World Anti-Doping Agency since January 1, 2016 imposed a ban on the meldonium drug, which is mostly common in Eastern Europe [6].

Thus, a number of information, social, political and technological challenges have led to the fact that the system of Russian sports management faced the urgent need to introduce dynamically a set of international standards in the field of control over the doping use by professional athletes.

\section{RESULTS}

It is noted that Russian sports organizations are increasing their activity in using the norms of international federations. This leads to the strengthening of the authority of international federations in certain sports, often contributing to the progressive reduction of the central government regulatory capacity, leaving it with only minor control functions in the field of sports. As a result, there is a phenomenon of split management of the sports sector, which leads to organizational confusions in the formation and implementation of sports policy [7].

Preparation for carrying out sports events of global importance in Russia adjusted sports and physical education public policy, and increased its efficiency in federal scale. Success in great competitions` organization demonstrated the potential of close cooperation between regional and municipal authorities with the federal central authorities as well as international organizations.

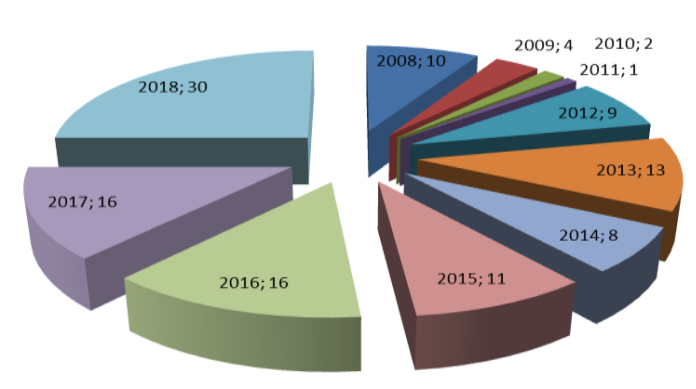

Fig. 1. Number of disqualified Russian athletes from 2008 to the beginning of 2018

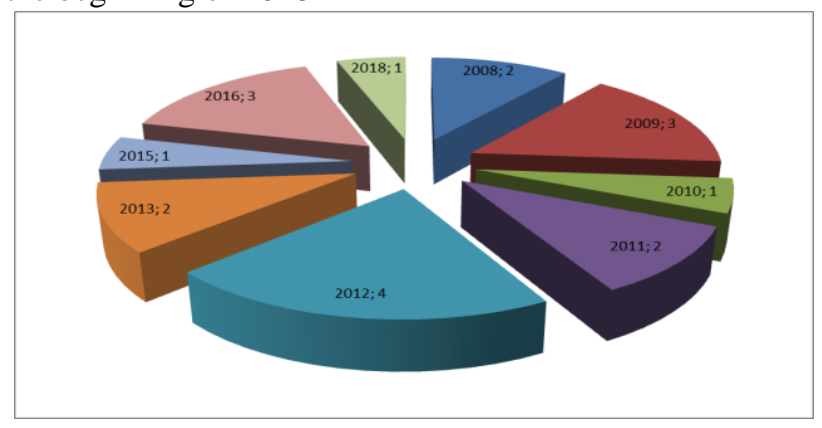

Fig. 2. Number of disqualified USA athletes from 2008 to the beginning of 2018

Various means may be may be opposed to such negative effects. However, one of the most effective
In this regard, aspects of constructive relations between subjects of Russian Federation and international nongovernmental structures were updated again. At the same time, the treaty regime of relations between regional territorial entities and international organizations on sports development seems to be a universal means of solving many problems, including the implementation of an effective government anti-doping policy [8].

It's necessary to support various forms of cooperation of international sports organizations and structural elements of public regulation system in the fields of physical culture and sports. It is worth noting that international sports organizations officially mark their activities as far from politics. However, they are undoubtedly influenced by a number of political actors. Therefore, international sports organizations ' positive impact on the Russian sports system can have the opposite effect. In the context of the sanctions policy against Russian Federation, there are increasing threats in turning international instruments for the development of the sports sector into a mechanism of economic and political impact.

Comparative analysis of the number of disqualified athletes from Russia and the USA in the period 2016-2018 demonstrates that suspicion of prohibited drugs used in training process gave reason to withdraw from international competitions 16 athletes from Russia and 3 athletes from the USA in 2016. And already 30 Russian athletes and only 1 athlete acting under a star-striped flag in 2018 (picture 1,2). This trend can be defined in terms of persistent negative stereotypes and discriminatory biases, deliberately introduced by opponents to the whole system of Russian sports and personally to Russian athletes.

approaches is based on the development of a national doping control system with the mandatory development of federal subjects` sports infrastructure, based on the principles of accessibility, social orientation and transparency.

The Republic of Tatarstan has a developed sports infrastructure and is one of the leaders among the regions of the Russian Federation in the field of physical culture and sports. Construction of comfortable sports facilities, comfortable conditions for sports creation, high popularity of various sports among the population contribute to the formation of a healthy lifestyle. Mass sports are actively introduced into the system of education and upbringing of the younger generation.

The Ministry of Sports of the Republic of Tatarstan is actively engaged in the development of sports infrastructure. However, insufficient attention has been still paid to public anti-doping policy.

Thus, Deputy General Director of RUSADA Margarita Pakhnotskaya in August 2018 stated that Tatarstan does not pay attention to anti-doping education [9]. Later in April 2019 Tatarstan was recognized by RUSADA as one of the worst regions in Russia on anti-doping achievement [10].

The mentioned RUSADA rating estimates the volume of anti-doping work according to the following criteria: 
updates in plans, the anti-doping section on the website of the regional authority, the quality of the report, the results of the activity of the responsible specialist for anti-doping support and the existence of a cooperation agreement with RUSADA.

As part of the program presented by the Sports Training Center of the Ministry of Sports (Republic of Tatarstan) "Anti-Doping - 2018," the following initiatives were implemented:

O In case of sport instructor's employment the RUSADA training course completion certificate became a mandatory confirmation of qualification;

○ Lectures courses on topical anti-doping issues for trainers of athletes and medical workers of sports federations of the Republic are given;

- Sport instructor's staff of republican children 's and youth sports schools began to take part regularly in work of round tables sessions on the topic "Basics of anti-doping support and control" [1].

- Medical staff of sports federations received clear instructions on correction of athlete's pharmacological programs for 2019.

- It was decided to deal with every case of doping scandal involving athletes of the Republic of Tatarstan in the Department of Sports Medicine of the Sports Training Center situated in Kazan.

- A website`s section of the Sports Training Center on Anti-Doping Support topic has been developed.

$\circ$ The discipline devoted to counteraction of doping was included in the skill's development programs for instructors of the Volga State Academy of Physical Culture, Sports and Tourism.

Over the past year, the Republic of Tatarstan has significantly improved its positions in the RUSADA rating. Now the Republic is at 46th (out of 85) position in RUSADA regions' rating $[11,12,13]$. Positive dynamics should be maintained further as Tatarstan is one of the main "suppliers" of trained sportsmen to the Russian sports teams. Sports merits of the Tatarstan athletes on the international stage confirm that the Republic has all necessary resources for highly qualified athletes training. Tatarstan consistently fulfils its obligations in the field of anti-doping regulation and control and fully supports principles of sports achievements without doping use.

\section{CONCLUSION}

The pathetic international situation, related with persistent negative stereotypes and discriminatory biases of Russian sports system reproduction, could be overcome by measures of cooperation and coordination in spheres of antidoping control and anti-doping education. Development of a national doping control system with the mandatory development of federal subjects` sports infrastructure, based on the principles of accessibility, wider international cooperation and transparency has to promote the further success of Russian athletes in international competition.

\section{References}

[1]. The Report on the Educational Seminar for Representatives of Regional Public Organizations, Sports Federations, Heads of Municipal Sports Institutions, Chief Trainers of National Sports Teams of the Republic of Tatarstan on the topic "Anti-Doping Support in the Republic of Tatarstan". 2018. (In Russ.)

[2]. Ratten V. International sports management: Current trends and future developments. Thunderbird International Business review. 2011; 53: 679-686. DOI: 10.1002/tie.20444

[3]. Jonathan G., Donna L. Soft Power, Sports Mega-Events and Emerging States: The Lure of the Politics of Attraction. Global Society. 2013: 27:4. 521-536. DOI: 10.1080/13600826.2013.827632.

[4]. Lednev V.A. Development of Market Relations in the Russian Sports Industry. Dokt. Diss. 2006. Moscow. (In Russ.)

[5]. Maryanchik N. Recognition Impossible: why Russia and WADA found themselves in a hopeless situation. RosBiznesKonsulting. 2017.

URL:https://www.rbc.ru/opinions/society/17/11/2017/5a0e93959a79 477b36622a1c. (In Russ.)

[6]. Schobersberger W., Dünnwald T., Gmeiner G. Story behind meldonium-from pharmacology to performance enhancement: a narrative review. British Journal of Sports Medicine 2017; 51: 22-25.

[7]. Yakubov Yu. D. Russian Regional Policy in the Field of Physical Culture and Sports Dokt. Diss. 2015. Kazan. (In Russ.)

[8]. Mehlman M.J, Banger E, Wright M.M. Doping in Sports and the Use of State Power // Saint Louis University Law Journal. 2006; 1573.

[9]. [Tatarstan became the worst region in anti-doping work. KazanFirst. 2019. URL: https://kazanfirst.ru/news/489193. (In Russ.)

[10]. Tatarstan pays little attention to anti-doping education. KazanFirst. 2018. URL: https://kazanfirst.ru/posts/472004. (In Russ.)

[11]. Nazarenko L.D., Kuznetsova Z.M., Meshcheryakov A.V. Conception of sport moral basis strengthening, not compatible with doping. The Russian Journal of Physical Education and Sport. 2018, 13(2), pp. 136-143. DOI: 10.14526/02_2018_322.

[12]. Alexsandr S. Kuznetsov. Russian Professor's meeting. Russian Journal of Physical Education and Sport. 2019, 14(1), pp. 17-22. DOI: 10.14526/2070-4798-2019-14-1-18-24

[13]. Anti-doping activities in the regions. Independent National AntiDoping Organization RUSADA, 2008-2019. URL: http://rusada.ru/education/rating/. 